J. Lake Sci. (湖泊科学) , 2013, 25(5): 649-654

http: //www. jlakes. org. E-mail : jlakes@niglas.ac.cn

(c) 2013 by Journal of Lake Sciences

\title{
丹江口水库上游武当山剑河水质空间差异性分析"
}

\author{
李 昆,李兆华 ${ }^{* *}$, 陈红兵, 李艳蓄, 余晓妹, 王 玲, 梅 新 \\ (湖北大学资源环境学院, 武汉 430062)
}

\begin{abstract}
摘 要: 丹江口水库是国家南水北调中线工程的水源地, 水质是决定工程成败的关键因素之一, 而始终困扰着水库水质 的是人库河流的水污染治理问题. 本文以丹江口水库上游的武当山剑河流域为研究对象, 在水环境调查基础上,选择有 代表性的水质参数及人为干扰因子对剑河进行水质空间差异性分析. 根据河流地理特征, 将剑河划分为上游、中游、下游 和太极湖河段调查单元, 其水环境管理目标分别为地表水 II 、III 、IV、III类标准 (GB/T 3838-2002). 结果表明: 在投肥养 鱼、污水管网缺损和污水处理率低等因素的影响下,剑河全河段总氮 (TN) 超标比较严重, 4 个调查单元均达不到水环境 管理目标要求. 总磷 $(\mathrm{TP})$ 、化学需氧量 $\left(\mathrm{COD}_{\mathrm{Cr}}\right)$ 、氨氮 $\left(\mathrm{NH}_{3}-\mathrm{N}\right)$ 在上游、中游河段分别达到地表水 II 类和 III 类管理要求, 但在下游分别只有 $64 \%$ 、64\% 和 $18 \%$ 达到IV 类水质要求,在太极湖河段 III类水质达标率分别为 $71 \%$ 、 $29 \%$ 和 0. 污染物浓 度整体呈现下游 >太极湖河段 > 上游 > 中游的趋势, 其中 TN 的污染最为严重, 浓度范围为 $2.27 \sim 13.51 \mathrm{mg} / \mathrm{L}$, 其次为 $\mathrm{NH}_{3}-\mathrm{N}(0.25 \sim 13.31 \mathrm{mg} / \mathrm{L}) 、 \mathrm{COD}_{\mathrm{Cr}}(7.0 \sim 95.5 \mathrm{mg} / \mathrm{L})$ 和 TP 浓度 $(0.01 \sim 0.79 \mathrm{mg} / \mathrm{L})$ 相对较低, 并不构成剑河的核心污 染. 通过水质空间差异性分析, 提出了针对性的污染源削减方案, 可以为河流水污染控制和丹江口水库水质管理提供科 学依据.
\end{abstract}

关键词: 丹江口水库;剑河;小流域;水质;空间差异性

\section{Spatial variations of the water quality in Jianhe River of Wudang Mountain in the upper reaches of Danjiangkou Reservoir}

\author{
LI Kun, LI Zhaohua, CHEN Hongbing, LI Yanqiang, YU Xiaomei, WANG Ling \& MEI Xin
}

(Faculty of Resources and Environment, Hubei University, Wuhan 430062, P. R. China)

\begin{abstract}
Danjiangkou Reservoir is the water source area of Mid-route of the South-to-North Water Transfer Project in China, and water quality is one of the critical factors to measure the success. However, the water quality has always been troubled by the water pollution control of input rivers of Danjiangkou Reservoir. This paper analyzed the spatial variations of the water quality in Jianhe River by analyzing regional representative factors such as water quality and man-made interferences based on ecological investigation of the water environment. On the basis of river geographical feature, Jianhe River was divided into four survey sections: upstream, midstream, downstream and Taijihu Reservoir, and the objectives of water environmental management were targeted to level II , III , IV and III (GB/T 3838-2002), respectively. The results show that under the influence of fertilizing aquaculture, lacking sewage network and a low rate in sewage treatment plant, TN of the whole Jianhe River exceeded threshold fairly and four survey sections all cannot reach the objectives of water environmental management; TP, $\mathrm{COD}_{\mathrm{Cr}}$, and $\mathrm{NH}_{3}-\mathrm{N}$ reached level II and III , respectively, in upstream and midstream, while only $64 \%, 64 \%$ and $18 \%$ in downstream reached level IV , and only $71 \%, 29 \%$ and 0 in Taijihu Reservoir reached level III , respectively. The overall pollution patterns are in the form of downstream $>$ Taijihu Reservoir > upstream > midstream, and the major pollutant in Jianhe River was TN $(2.27-13.51 \mathrm{mg} / \mathrm{L})$, followed by $\mathrm{NH}_{3}-\mathrm{N}$ $(0.25-13.31 \mathrm{mg} / \mathrm{L}), \mathrm{COD}_{\mathrm{Cr}}(7.0-95.5 \mathrm{mg} / \mathrm{L})$ and $\mathrm{TP}(0.01-0.79 \mathrm{mg} / \mathrm{L})$. Concentrations of $\mathrm{COD}_{\mathrm{Cr}}$ and $\mathrm{TP}$ were low and not the main pollutants of Jianhe River. According to the difference analysis of the water quality, the targeted reduction plan was proposed, which provided the scientific basis for better management of water pollution in Danjiangkou Reservoir and water pollution
\end{abstract}

* 国家民生科技计划项目(2011 MSB5007) 资助. 2012-11-13 收稿;2012-12-11 收修改稿. 李昆, 男,1987 年生, 硕 士研究生;E-mail:281462879@ qq. com.

** 通信作者;E-mail:zli@ hubu. edu.cn. 
control of the river.

Keywords: Danjiangkou Reservoir; Jianhe River; small watershed; water quality; spatial variation

河流水质系统是自然与社会系统综合作用的复合系统, 是反应水体质量状况的指标, 其内容包括各种 水体中的天然本底值、河流携带的悬浮物、水中污染物等的含量和成分及其变化. 水质变化不仅反映了各种 自然因素如气象水文特征、流域特征、地质状况等在河流中形态表征的变化, 同时也体现了流域范围内社会

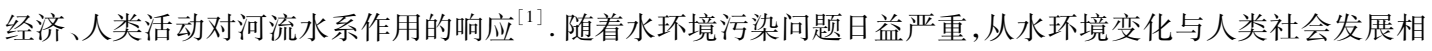
互作用和耦合的角度出发, 河流水质变化的研究已成为世界各国众多学者关注的热点问题 ${ }^{[2]}$. 1990s 后随着 经济的发展, 全球水体污染变得越来越严重, 水质研究的方法和模式呈现多元化, 出现了各种数学方法和模 型来分析水质问题和预测未来水质的演化趋势, 对全球水质的研究给予了巨大的贡献 ${ }^{[3-4]}$. 我国水质分析的 研究方向主要集中在大江、大河、湖泊和地下水方面, 研究中重视的是天然水离子的变化,污染指标方面的 研究较少或不够全面 ${ }^{[5]}$, 对于波动性大、稳定性差、分异性强的小流域水质空间变异性的研究尚不多见 ${ }^{[6]}$.

丹江口水库是亚洲最大的人工淡水湖, 是国内水质最好的大型水库之一, 按地面水环境质量标准综合 评估, 库区水质达到 I 类标准, 是南水北调中线的理想水源地 ${ }^{[7]}$, 对其研究基本集中在丹江口库区水质及其 下游径流的特性等方面 ${ }^{[8-10]}$, 但是对其上游的武当山境内由社会经济发展和人口变化造成库区上游河流逐 渐加重的污染状况却研究较少. 随着武当山城区的发展, 作为唯一流经城区的剑河成为纳污水体, 污染严 重, 水质恶化, 成为旅游景观的一大脈病, 沿岸人民生活受到影响, 同时对丹江口库区水质产生污染, 使南水 北调中线工程得不到水源保障. 本文依据剑河 45 个监测断面的水质分析数据、剑河流域内各污染源的排放 量和排污口的情况, 以对剑河流域的水质空间差异、富营养化程度和污染原因等方面进行较详尽和全面的 分析, 克服了以往逐点评价水体的片面性, 揭示了流域内的生态环境和人类活动对水质的影响, 为今后制定 水资源可持续开发利用规划、流域水污染控制和水土流失治理提供科学依据, 以改善城区水生态环境, 消除 对南水北调水源地的污染, 实现“清水人库、清水北送”的目标.

\section{1 研究区概况}

剑河 ( $32^{\circ} 23^{\prime} \sim 32^{\circ} 35^{\prime} \mathrm{N}, 110^{\circ} 55^{\prime} \sim 111^{\circ} 14^{\prime} \mathrm{E}$ ) 位于丹江口水库上游的武当山旅游经济特区内, 流域面积 $47.2 \mathrm{~km}^{2}$, 河道狭窄, 陡坡水流湍急, 属山溪性河流, 主河道长度为 $26.5 \mathrm{~km}$, 流域内多年平均降雨量为 $885.7 \mathrm{~mm}$, 降水总量为 $4129.5 \times 10^{4} \mathrm{~m}^{3}$. 由龙潭口处进人城区至乔家院桥处出城流人太极湖河段, 最后顺流而下汇人丹 江口水库. 依据国务院《丹江口库区及上游水污染防治和水土保持规划》(国函[2006]10 号)、《湖北省地表 水环境功能区划》(鄂政办发〔2000]10 号) 和十堰市环境保护局的实际要求将其分为 4 段: 上游剑河水库河 段 (发源于武当山东麓倒开门,止于剑河水库水坝) 全长 $17 \mathrm{~km}$, 管理目标 II 类水质; 中游自然河段 (剑河水 库水坝至龙潭口) 全长 $1 \mathrm{~km}$, 管理目标 III 类水质; 下游城区河段 (龙潭口至乔家院桥处) 全长 $5 \mathrm{~km}$, 中间布有 5 个橡皮坝, 管理目标 $\mathrm{IV}$ 类水质; 太极湖河段 (乔家院桥至太极湖生态截污闸) 全长 $3.5 \mathrm{~km}$, 管理目标 III 类水 质. 剑河于 2011 年纳人丹江口库区上游河流监测范围, 流域内总人口 3.85 万, 其中城镇人口 2 万, 流动的旅 游人口每年 210 万, 有 5 家规模以上的工业企业是以剑河为受纳水体, 其中有一家位于太极湖左岸, 污水未 经处理直接排人太极湖. 剑河两岸铺设污水收集管道, 左岸污水进人太极湖右岸的污水处理厂, 右岸污水因 管道的缺失在乔家院处排人剑河, 但是以暗管形式进行排污的排污管道共有 38 个, 全部分布在下游地区.

\section{2 材料与方法}

\section{1 数据来源}

水质检测和分析数据来自实地调查和实验室分析; 排污口数量及排污类型来源于实地调查; 剑河流域 内各污染源的排放量数据来源于武当山旅游经济特区污染普查生活源档案、武当山旅游经济特区污染普查 工业污染源档案、武当山旅游经济特区农业统计年报、武当山旅游经济特区环境质量年报及其它相关报表.

\section{2 研究方法}

以《地表水环境质量标准》( GB/T 3838-2002) 为参照标准, 结合剑河的基础资料,运用 GPS 对剑河流 
域的监测断面进行定位. 因上游地区自然河床内 的河水清澈, 仅在剑河水库处布设 2 个监测断 面; 中游地区水质较好,在此布设 1 个监测断面; 下游地区流经城区, 水质污染严重, 两岸分布大 量小型排污口, 在龙潭口处布设第 1 个监测断 面, 随后每隔 $150 \mathrm{~m}$ 左右布置下一个断面, 另外 在每一个暗管排污口处增加 1 个监测断面, 共设 28 个监测断面; 太极湖河段水面宽广, 排污口较 少, 小区域内的水质变化平缓, 故每隔 $300 \mathrm{~m}$ 左 右布设 1 个监测断面, 共设 14 个监测断面至太 极湖生态截污闸处结束 (图 1). 于 2011 年 11 月 在上述监测断面采集瞬时水样, 水样的保存与运 输、采样体积及使用容器、洗涤方法严格按照《水 和废水监测分析方法》进行 ${ }^{[11]}$. 化学需氧量 $\left(\mathrm{COD}_{\mathrm{Cr}}\right)$ 、总氮 $(\mathrm{TN})$ 、总磷 $(\mathrm{TP})$ 、氨氮 $\left(\mathrm{NH}_{3}-\mathrm{N}\right)$ 分别采用酸性重铬酸钾法 ( GB/T 11914-1989)、 碱性过硫酸钾氧化一紫外分光光度计法 (GB/ T 11894-1989)、钼锑抗分光光度法 ( GB/ T 11893-1989) 和纳氏试剂分光光度法 (GB/ T 7479-1987) 测定, 所有样品均设置 2 个平行 样, 测量分析的相对标准偏差均保持在 5\% 以内. 同时运用统计学的理论和方法, 结合研究区河流

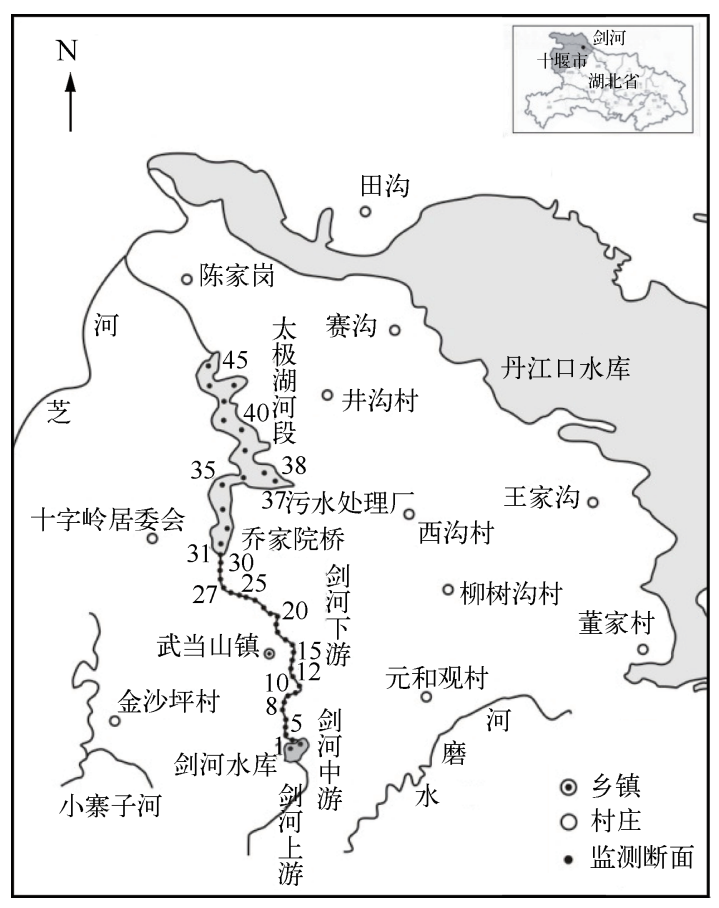

图 1 剑河水体监测断面布设

Fig. 1 Distribution of monitoring sections in Jianhe River 的人为用途、水域生态保护及生物多样性的要 求,对河流水质的空间变异性进行研究,从而实现对污染物可能的变化趋势进行分析.

\section{3 结果}

\section{1 总氮}

$\mathrm{TN}$ 在剑河流域内均为劣 $\mathrm{V}$ 类水质, 没有达到管理目标, 污染非常严重, 最大值为 $31^{\#}$ 断面的 $13.51 \mathrm{mg} / \mathrm{L}$, 最小值为 $2.27 \mathrm{mg} / \mathrm{L}$, 平均值为 $6.29 \mathrm{mg} / \mathrm{L}$, 龙潭口附近的水质 $\mathrm{TN}$ 含量相对较低, 整个下游呈增加的趋势, 太极湖河段总体呈下降的趋势, 在乔家院桥处的 $30^{\#} 、 31^{\#}$ 断面和污水处理厂出水口处的 $37^{\#}$ 监测断面的 TN 浓度显著增加 (图 2).

\section{2 氨氮}

$\mathrm{NH}_{3}-\mathrm{N}$ 空间变异趋势与 $\mathrm{TN}$ 具有极其相似的规律, 但是其在上游和中游分别达到地表水 II 类和 III 类管 理目标,下游河段 $\mathrm{NH}_{3}-\mathrm{N}$ 浓度逐渐增大,合格率仅为 $18 \%$,太极湖河段全部不合格但总体呈下降趋势; 最大 值为 $31^{\#}$ 断面的 $13.31 \mathrm{mg} / \mathrm{L}$, 最小值为 $0.25 \mathrm{mg} / \mathrm{L}$, 平均值为 $3.85 \mathrm{mg} / \mathrm{L}$, 从第一号橡胶坝前 $400 \mathrm{~m}$ 左右的 $14^{\#}$ 点往后大部分属于劣 $\mathrm{V}$ 类水, 在 $30^{\#} 、 31^{\#}$ 和 $37^{\#}{ }^{*} ⿺_{斤}$ 面变化较大 (图 2).

\section{3 化学需氧量}

$\mathrm{COD}_{\mathrm{Gr}}$ 在上游和中游合格,在下游和太极湖河段的合格率为 $64 \%$ 和 $29 \%$. 最大值出现在 $19^{\#}$ 监测断面, 为 $95.5 \mathrm{mg} / \mathrm{L}$, 最小值出现在 $24^{\#}$ 断面, 为 $7 \mathrm{mg} / \mathrm{L}$, 平均值为 $34.43 \mathrm{mg} / \mathrm{L}$. 龙潭口附近的 $\mathrm{COD}_{\mathrm{Cr}}$ 含量较低, $15^{\#} \sim$ $23^{\#}$ 断面间的浓度处于较高水平, $30^{\#} 、 36^{\#} 、 37^{\#}$ 断面的浓度急剧加大. 在第一号橡胶坝前 $200 \mathrm{~m}$ 左右的 $15^{\#}$ 断 面至第三号橡胶坝附近的 $23^{\#}$ 断面之间的 $\mathrm{COD}_{\mathrm{Cr}}$ 含量全部超过地表水 $\mathrm{IV}$ 类标准. 流域内沿程变化呈先升后降 趋势,但是波动较大, 在太极湖生态截污闸前达到 III类水质标准 (图 2).

\section{4 总磷}

$\mathrm{TP}$ 的空间变异趋势是在上游和中游分别达到地表水 II 类和 III 类管理要求, 下游河段 TP 含量逐渐增大, 


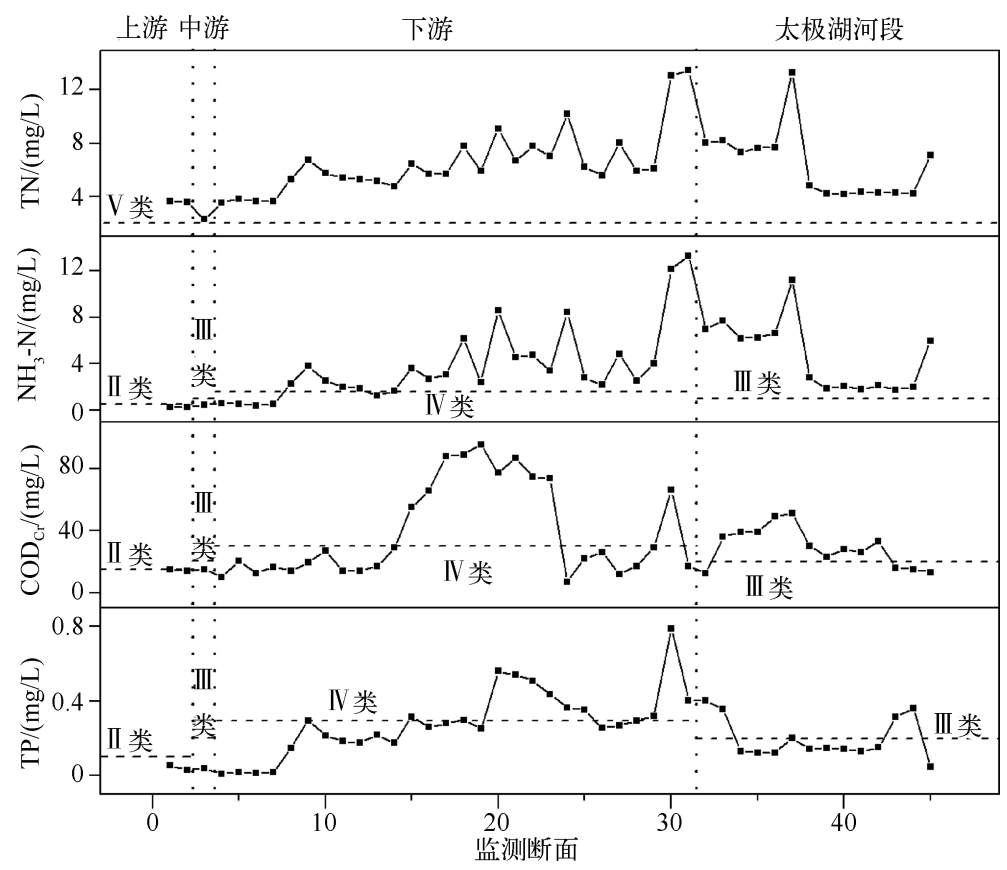

图 2 剑河水质参数变化趋势

Fig. 2 Change trend of water quality parameters along Jianhe River

达到 IV 类水管理目标的有 18 个,合格率为 $64 \%$; 太极湖河段 TP 含量相对较低, 大部分达到地表水 III 类水质 标准, 合格率为 $71 \%$; 最大值出现在 $30^{\#}$ 监测断面, 为 $0.79 \mathrm{mg} / \mathrm{L}$, 最小值出现在 $4^{\#}$ 断面, 为 $0.01 \mathrm{mg} / \mathrm{L}$, 平均 值为 $0.24 \mathrm{mg} / \mathrm{L}$, 总体变化较为平缓 (图 2).

\section{4 讨论}

根据水质综合评价 ${ }^{[12]}$, 剑河水质全部为劣 $\mathrm{V}$ 类, 水质空间变异的根本原因是人类活动造成营养物质的 大量输人和河流的自净能力有限. 营养物质的来源有城乡生活污水、旅游污水和工业污水; 农业土壤中流失 的肥料;畜禽养殖业中排出的畜禽粪便;沉积物中氮和磷的释放等.

1) 剑河上游的剑河水库监测断面只有 $\mathrm{TN}$ 超标, 呈劣 $\mathrm{V}$ 类, 污染比较严重, 但是其 $\mathrm{NH}_{3}-\mathrm{N}$ 含量很低, 初 步断定是剑河水库存在不合理的投肥养鱼行为造成 TN 暂时性超标现象 ${ }^{[13-14]}$, 同时其生态结构单一而薄弱, 水生生物生长区域小、水体透明度小, 大量的沉水植物和其他水生生物的生长受到限制, 从而在投肥后影响 剑河水库的生态系统, 减弱其物质的循环和交换, 使其水体自净能力下降, 难以完全降解和消化氮元素, 导 致水质恶化.

2) 中游河段的水质空间变化平稳, 污染物浓度较上游有所下降,除 TN 受上游水质影响未达标外, 其余 各污染因子均达到 III 类水质标准, 主要是由于中游河段为自然河堤, 沿岸为山谷, 没有各种工业和农业等因 素的干扰, 通过水体的自然降解使污染物含量逐渐降低.

3) 下游河段是资源类产业和人口集聚密集的流域,分布有 2 万左右的城镇人口、每年近 210 万人次的 游客和流域内的大部分工矿企业, 在工业废水、生活用水排放量急剧加大和流域天然来水量较少的情况下, 一方面水体的自身净化能力下降, 另一方面流域污水处理措施未能改善, 导致下游的污染日益加重和流域 内水质类别急剧上升. $8^{\#} \sim 12^{\#}$ 监测断面之间的居民区以暗管形式排放的生活污水受河水的紊流作用影响, 在流动中逐渐与河水混合、扩散, 导致该段区域的污染物浓度显著上升和后段水质相对下降, 但根本原因是 区域缺乏污水处理设施和城市排水管网不健全导致的雨污分流不彻底以及暴雨期间大量生活污水溢流人 河, 因生活污水中的有机物含量高, $15^{\#} \sim 23^{*}$ 断面间的 $\mathrm{COD}_{\mathrm{Cr}}$ 浓度处于较高水平. TN、TP、 $\mathrm{COD}_{\mathrm{Cr}}$ 和 $\mathrm{NH}_{3}-\mathrm{N}$ 的 
浓度随沿途排污口数量的增加而逐渐上升, 在乔家院桥处的 $30^{\#} 、 31^{\#}$ 断面直线增加, 主要原因是截污管道未 接人污水处理厂, 造成大量工业废水和生活污水不经任何处理直接集中排人剑河, 此处生活污水排放量与 水体氮、磷含量呈显著正相关,氮、磷等营养元素污染的水期变化特征与生活污水排放的季节变化规律有较 强的同步性,接近排污口处的水体水质各项指标的浓度极高. 下游河段的水质空间变异基本反映出流域人 口分布、产业布局和经济发展对水环境的重大影响.

4) 太极湖河段的污染物总体上都呈现下降的趋势, 水质尽管通过水体的净化作用较下游有所改善,但 仍然不能达到管理要求的 III类水质标准. $37^{\#}$ 监测断面的各污染物指标急剧增大,造成这种现象的原因是位 于该监测断面的日处理能力 $7000 \mathrm{t}$ 的污水处理厂出水仅达到《城镇污水处理厂污染物排放标准》 (GB/T 18918-2002) 一级 B 标准, 处理率低, 污水处理量小于污水排放量, 仍有部分污水未经处理随尾水 一起排人剑河,对该断面的水质产生严重的污染. 太极湖水体无径流补给量,整个水体基本处于静止状态, 水力交换极其缓慢,加上河体不规则,易形成死角, 导致污染物分布不均, 难以稀释、扩散,使局部水域水质 恶化, 加剧水体富营养化水平, 整体处于重度富营养化状态, 氮、磷等主要营养物质含量甚至超过丹江口库 区的 $5 \sim 7$ 倍 ${ }^{[15]}$.

剑河流域水环境问题与人为经济活动和生产生活方式密切相关, 流域营养盐污染结构已悄然发生变 化, 并已经显现环境生态效应 (富营养化). TN、TP 一定程度呈上升趋势, 说明流域水质的硬度日趋增高. $\mathrm{COD}_{\mathrm{Cr}}$ 污染相对较轻表明该流域的水环境条件适合水中无机和有机污染物的分解,使水体的无机和有机污 染物含量下降 ${ }^{[16]}$. 水质在下游河段总体上升和太极湖河段总体下降的趋势反映了剑河污染中点源污染的贡 献率大于面源污染, 在点源污染的众多因素中, 城镇生活污水是主导因素, 流域内的城镇人口和工业设施基 本集中在下游区域,而农田、林地等主要分布于太极湖的周边区域,所以随雨水、渗透等而来的面源污染物 对剑河的污染相对较轻. 污染如果不加以控制, 到 2020 年 TN 排放量将达到环境容量的 $215.15 \%, \mathrm{COD}_{\mathrm{Cr}}$ 、 $\mathrm{NH}_{3}-\mathrm{N}$ 和 TP 到 2020 年的排放量分别为环境容量的 $235.38 \%$ 、175.33\% 和 $133.21 \%{ }^{[17]}$. 针对目前的污染现 状和原因可以采取以下治理措施来达到水质管理要求,在上游剑河水库处坚决禁止投肥养鱼行为以杜绝氮 元素的污染; 对下游城区段的排污口和缺损的污水管道实施截污纳管工程进行改造,让污水进人污水处理 厂处理, 同时在河道中安装曝气复氧装置以提高水体溶解氧, 消除水体黑臭现象 ${ }^{[18]}$; 太极湖河段的污水处理 厂在提高污水出水标准的同时其尾水可通过人工湿地的深度处理以达标排放, 太极湖河段的水面可以通过 生物浮岛工程对水质进行净化.

本研究将流域内不同河段区域的生态环境、资源条件和经济社会发展水平等客观差异合理划分出多种 主体功能区,通过比较流域内不同河段分区的功能与水质之间的关系, 可以进一步认识流域水资能区的空 间差异性、水生态系统服务功能的空间分区特征以及各项生态服务功能重要性的总体分异规律, 使流域水 质变化与人类社会之间关系的探究更为简易；同时剑河流域与丹江口水库之间存在着紧密的物质、能量交 换和生态联系,其流域内的污染信息将直接反映丹江口库区的水体污染水平,掌握该区域水体氮、磷等污染 物的空间变异特征及其营养形态结构, 以期为剑河流域水污染防治及丹江口库区水资源保护提供理论基 础. 但是剑河流域 2011 年才进人丹江口库区上游河流的监测范围, 本次监测为剑河水质第一次详细监测, 同时随着流域人口增加、畜离养殖、化肥施用、工矿企业等众多经济开发活动以及气候变化的叠加影响,剑 河水环境和生态系统的变动趋于复杂化,目前的水环境监测项目、监测频率和评价体系还无法满足对水环 境的动态监控和水质管理的要求,如果能将此工作延续,找出空间差异在时间上的变异规律, 从而可以准确 地预测出下一阶段河流水质的空间分布特征, 这将对研究区河流水环境的保护与治理有重要的意义.

\section{5 结论与建议}

1) 受不同河段自身条件的差异、不同区域污染来源的差异和河水流动性的差异等因素的影响,研究区 河流水质参数呈现出不同的空间变异特征. 主要污染源集中在下游和太极湖河段,乔家院桥处断裂的污水 管道和污水处理厂是污染物浓度的明显转折点, 暗管排污口对水质也造成了严重的影响,污染整体呈现下 游河段 >太极湖河段 > 上游河段 > 中游河段的空间差异性,点源中的城镇生活污水为主要污染源.

2) 各水质参数污染均相当严重, 尤以富营养化指标氮最为显著, 其中总氮的平均值已达到《地表水环 
境质量标准》 $(\mathrm{GB} / \mathrm{T} 3838-2002)$ 中 $\mathrm{V}$ 类水质的 3 倍, 是下一步污染控制的重点, 其次为 $\mathrm{NH}_{3}-\mathrm{N} 、 \mathrm{COD}_{\mathrm{Gr}}$ 和 $\mathrm{TP}$ 的污染, 各污染物浓度总体呈先升后降趋势.

3) 针对目前剑河流域水质差异性特点, 治理的重点是对上游的剑河水库禁止投肥养鱼;下游地区的暗 管排污口和断裂的截污管道实施截污纳管和曝气复氧; 太极湖河段的污水处理厂提高其出水标准,同时可 以运用人工湿地等工艺对尾水进行深度处理, 这样才能有效地发挥其防护和净化水质的功能作用, 彻底改 善剑河流域的生态环境.

\section{6 参考文献}

[1] 王 莉,胥鹏海, 宋 涛等. 浅河水质变化趋势及原因分析. 西北大学学报: 自然科学版, 2011,41 (3):503-506.

[2] 郭 巍.渭河陕西段主要监控断面水质变化趋势分析. 安全与环境工程,2010,17 (5) :47-50.

[ 3 ] Machate T, Noll H, Behrens H et al. Degradation of phemn-threne and hydraulic characteristics in a constructed wetland. Water Research, $1997,31(3): 554-560$.

[ 4 ] Gert K. Trends in the acidification of groundwater. Groundwater quality management(proceedings of the GQM 93 Conference held at Tallinn, September 1993. LAHS Publ,1994,200:5-15.

[5] 黄渏平. 太湖水环境及其污染控制. 北京:科学出版社, 2001 .

[6] 李 波, 兴培民. 淮河流域及洪泽湖水质的演变趋势分析. 长江流域资源与环境,2003,12(1):67-73.

[7] 长江流域水资源保护局. 长江省界水体水环境质量状况通报. 武汉: 湖北省武汉市长江流域水资源保护局,2009.

[8] 陆国宾, 刘 轶, 邹响林等. 丹江口水库对汉江中下游径流特性的影响. 长江流域资源与环境, 2009, 18 (10): 959-963.

[9] 章厚玉,林云发,杨德安等. 丹江口水库汉江干流库区淤积分析. 长江科学院院报,2010,27(9):1-5.

[10] 孔令惠, 蔡庆华, 徐耀阳等. 丹江口水库浮游轮虫群落季节变动特征及其与环境因子的关系. 湖泊科学, 2010,22 (6) :941-949.

[11] 国家环境保护总局《水和废水监测分析方法》编委会. 水和废水监测分析方法:第 4 版. 北京: 中国环境科学出版 社, 2002 .

[12] 李兆华,李瑞勤. 清江水污染防治研究. 北京:科学出版社, 2010 .

[13] 李程亮, 朱培欣, 梁运祥. 生物渔肥施用后氮磷元素在水体中留存规律的研究. 湖北农业科学, 2011, 50 (21): 4374-4377.

[14] 张根芳, 许式见, 刘其根等. 小型水库不同蚌、鱼混养模式排放水的水质分析. 大连海洋大学学报, 2010,25 (3) : 253-259.

[15] 黄 伟,李忠锋,李 超等. 基于因子分析定权法的丹江口水库水体营养度综合评价. 环境科学与管理,2009,34 (6) : 164-168.

[16] 李俊英,李素清,韩锦涛. 汾河上游流域沿程典型水样点水质变化分析. 中国水土保持科学,2011,9(3):59-64.

[17] 焦 栗,李 昆,赵 莎等.武当山剑河水环境容量分析. 水资源研究,2012,(4):289-292.

[18] 余晓妹,李兆华,李 昆等. 剑河城区段曝气复氧方案设计. 环境保护前沿,2012,2(3):40-44. 